\title{
Demountable piezoelectric transducer holder for use at low temperatures
}

\author{
M. B. Manning, a) M. J. Moelter, and C. Elbaum \\ Department of Physics and Metals Research Laboratory, Brown University, Providence, \\ Rhode Island 02912
}

(Received 24 October 1986; accepted for publication 19 February 1987)

\begin{abstract}
We present a design for a piezoelectric transducer holder for use at low temperatures, which is easily constructed and assembled. Improved acoustic signals with "ringing" eliminated were reliably obtained. The standard problems of demountability, electrical integrity, and leak tightness in the presence of hiquid helium at moderate pressures were resolved.
\end{abstract}

Ultrasonic measurements on liquid and solid helium using piezolectric transducers have practical problems not found in room-temperature experiments. Solid helium exists only under pressures of at least 25 atm; therefore, sealing the sample cell and providing a reliable electrical feedthrough are necessary. Both liquid and solid helum are low acoustic impedance materials so the backing and mounting of the transducer are important considerations in attempts to maintain signal quality.

We have designed and used a transducer holder which is easily demounted, self-contained, is easily made free from electrical shorts and breaks, and was proven leak-tight up to at least $60 \mathrm{~atm}$, including tightness in superfuid helium throughout its entire pressure range. We consistently obtained good quality ultrasonic signals with a minimum of "ringing." Central to the solution is the versatile, filled epoxy, Stycast $2850 \mathrm{GT}$, along with Catalyst 43 which we found worked best. ${ }^{2}$ Methods for constructing low-temperature epoxy feedthroughs are abundant, ${ }^{2,3}$ and various material properties of Stycast $2850 G T$ at low temperatures are well documented. ${ }^{4}$

The holder, shown in Fig. 1, was constructed as follows. A brass holder body was machined with the faces of the holder parallel to ensure that opposing transducers were parallel when the holders were mounted on opposite sides of the cell, fiush with the cell walls. A piece of $\frac{3}{16}-$ in.-0.d. copper tubing was brazed into the holder and then machined so a tapered stub approximately $\frac{3}{16}$ in. in length was formed. The tapered copper was etched with nitric acid, rinsed with water, and dried with alcohol. ${ }^{2}$ In order to mount the transducer in the holder, the backing and electrical connections needed to be made.
A roughened cone of copper (see Fig. 1) with a copper wire attached was soldered with indium to a coaxially plated -in.-diam $\mathrm{LiNbO}_{3}$ ultrasonic transducer. The cone was approximately $\frac{3}{16}$ in. in height and $\frac{1}{8} \mathrm{in}$. in diameter, which matched the active area of the transducer. For use at frequencies in the neighborhood of $10 \mathrm{MHz}$, the surface was roughened on a 0.020 -in. scale (waveiength of longitudinat sound in copper) in an effort to prevent coherent reflections of the $10-\mathrm{MHz}$ sound from the conical surface.

The holder body described above was then filled with

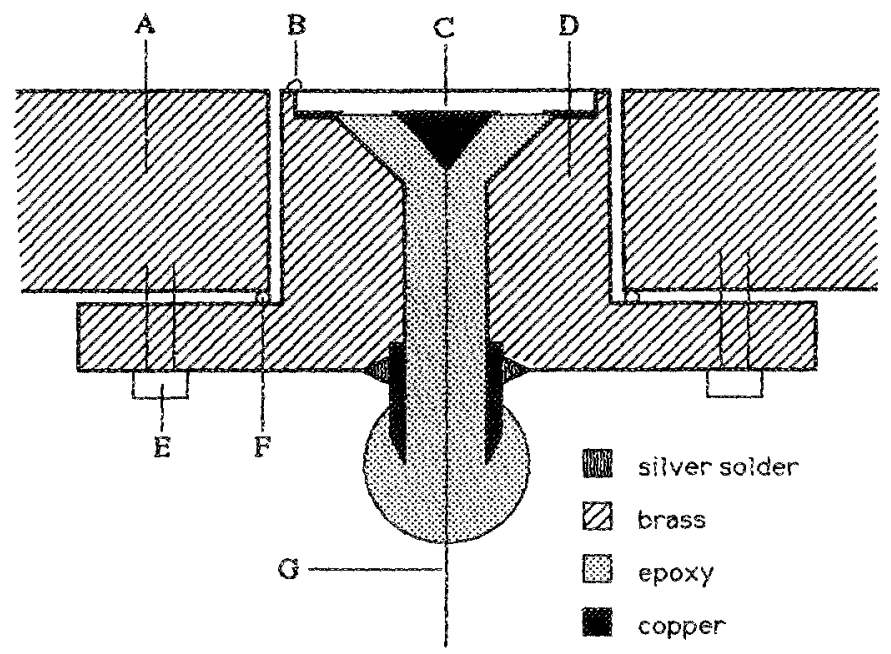

Fici. 1. Schematic of the holder, shown here attached to cell body. (A) cell body, (B) transducer ground lead, (C) piezoelectric transducer, (D) holder, (E) mounting screw, (F) indium O-ring, (G) transducer signal lead. 
epoxy and the transducer was placed on the small ledge. A Teflon piug prevented the epoxy from flowing through the feedthrough hole. Curing in a $150^{\circ} \mathrm{F}$ oven for $12 \mathrm{~h}$ followed. After the first curing the Tefion plug was removed and a bead of epoxy was applied to the feedthrough side completely covering the tapered copper piece. With the electrical wire drawn straight out to avoid shorting, the entire assembly was again baked for $12 \mathrm{~h}$ at $150^{\circ} \mathrm{F}$. Finally, the completed holder was mounted on the cell body with four 2-56 stainless cap screws and sealed with an indium O-ring. To ensure that the transducer would be parallel to the reflecting surface located on the opposite side of the cell, ultrasonic signals in alcohol were monitored during this process. Using the puise-echo method, the echo train was monitored, as the mounting screws were tightened, and signal amplitude was maximized while maintaining an overall exponential decay.

The final design addressed the following difficulties. (1) The indium soldering of the copper cone to the transducer prevented any loss of mechanical or electrical connection. Indium remains more malleable than regular solder down to liquid-nitrogen temperature $(77 \mathrm{~K})$. Since most of the thermal contraction takes place between room- and liquid-nitogen temperatures a less rigid bond is desirable in this range. (2) Ultrasonic signal quality in low acoustic impedance materials has been discussed by several authors. ${ }^{6,7}$ The results of Altman and Beyer for weakly back-loaded transducers show the undesirable features of "ringing" and nonexponential decay of the signals. These effects have been observed experimentally with earlier holder designs, making it diff- cult or impossible to carry out reliable measurements. In the present design the copper cone firmly attached to the transducer was also firmly attached to the epoxy. This produces an effective back-loading of the transducer and reduces the characteristic "ringing" when radiating sound into low acoustic impedance materials, such as liquid or solid helium $\left(z \approx 10^{4} \mathrm{cgs}\right.$ ). (3) The epoxy seal at the tapered copper tube was leak-tight through more than 100 cycles of cooling and warming between $0.6 \mathrm{~K}$ and room temperature, thus demonstrating its viability for low-temperature experiments.

This work was supported by the National Science Foundation through Grant No. DMR-8304224.

\footnotetext{
a) Present address: Sippican, Inc. Marion, Massachusetts 02738.

${ }^{3}$ Emerson-Cumming, Inc., Canton, MA 02021.

${ }^{2}$ A. C. Anderson, Rev. Sci. Instrum. 39, 605 (1968).

${ }^{3}$ G. J. Butterworth, Cryogenics 15, 40 (1975); F. Mathu and H. C. Meijer, Cryogenics 22, 428 (1982).

${ }^{4}$ M. J. Mackowski, K. E. West, D. A. Samsel, L. B. Holdeman, and P. N. Peters, Cryogenics 16, 45 (1976); D. T. Corzett, A. M. Keller, and P. Seligmann, Cryogenics 16, 505 (1976).

${ }^{5}$ Indium Corp. of America, New York, NY.

${ }^{6}$ H. E. Altman and R. T. Beyer, J. Acoust. Soc. Am. 59, 545 (1976).

'E. Kittinger and W. Rehwald, Uitrasonics 15, 211 (1977).
}

\title{
UHV sample mount for the temperature range $10-1300 \mathrm{~K}$
}

\author{
R. E. Palmer, P. V. Head, and R. F. Willis \\ Cavendish Laboratory, Madingley Road, Cambridge CB3 OHE, United Kingdom
}

(Received 9 January 1987; accepted for publication 10 February 1987)

\begin{abstract}
We describe a sample mounting facility capable of cooling a graphite crystal to temperatures of around $10 \mathrm{~K}$ (to enable investigation of low-temperature physisorbed phases) and which at the same time permits the crystal to be heated to $1300 \mathrm{~K}$ for surface cleaning. A demountable resistive heating mechanism avoids the conductive loading of the sample which normally inhibits the attainment of very low temperatures.
\end{abstract}

The preparation of clean crystal surfaces for surface-science experiments in ultrahigh vacuum (UHV) almost always involves heating the crystal to temperatures of hundreds or even thousands of degrees above room temperature to boil off contaminants. ${ }^{1}$ When the crystal is to be cooled to liquidhelium temperatures to investigate low-temperature surface phenomena conficting demands are introduced, primarily because residual sources of heat need to be eliminated in the "cooling mode." Here we describe a mounting configuration to allow a pyrolytic graphite crystal to be cleaned by direct resistive heating to $1300 \mathrm{~K}$ prior to cooling to temperatures down to $10 \mathrm{~K}$ (in this case, to study the phases of physi- sorbed molecules like $\mathrm{O}_{2}$ and $\mathrm{N}_{2}$ with high-resolution electron energy-loss spectroscopy ${ }^{2}$ ). It appears that the method employed here to achieve this very wide range of temperature promises success for a number of different crystals which might be studied.

Resistive sample heating is frequently used as a straightforward means of cleaning a crystal's surface. The problems as far as achieving cryogenic temperatures is concerned center on loading the sample with heat conducted down the current-carrying wires and also on the excellent thermal contact required between sample and cold finger to reach temperatures only a few degrees above that of the helium 